\title{
Population dynamics of the intertidal barnacle Semibalanus balanoides at three European locations: spatial scales of variability
}

\author{
S. R. Jenkins ${ }^{1, *}$, P. Åberg ${ }^{2}$, G. Cervin ${ }^{2}$, R. A. Coleman ${ }^{3}$, J. Delany ${ }^{4}$, S. J. Hawkins ${ }^{3}$, \\ K. Hyder ${ }^{3}$, A. A. Myers ${ }^{4}$, J. Paula ${ }^{5}$, A.-M. Power ${ }^{4}$, P. Range ${ }^{5}$, R. G. Hartnoll ${ }^{1}$ \\ ${ }^{1}$ Port Erin Marine Laboratory (University of Liverpool), Port Erin, Isle of Man IM9 6JA, United Kingdom \\ ${ }^{2}$ Department of Marine Botany, Göteborg University, Box 461, 40530 Göteborg, Sweden \\ ${ }^{3}$ Division of Biodiversity and Ecology, School of Biological Sciences, University of Southampton, Bassett Crescent East, \\ Southampton SO16 7PX, United Kingdom \\ ${ }^{4}$ Department of Zoology and Animal Ecology, University College Cork, Lee Maltings, Prospect Row, Cork City, Ireland \\ ${ }^{5}$ Laboratório Marítimo da Guia, Estrada do Guincho, 2750 Cascais, Portugal
}

\begin{abstract}
Spatial variability in the population dynamics of the intertidal acorn barnacle Semibalanus balanoides was investigated using a hierarchical sampling programme. Variability in a number of population parameters (size distribution, density, \% cover, absolute growth and instantaneous mortality) was determined separately for new recruits and adults over 3 spatial scales. Three locations, SW Ireland, the Isle of Man and the west coast of Sweden, which cover a large part of the European range of this species, were selected to investigate variability over a large spatial scale (100s of kilometres). Two smaller scales, shore (1000s of metres) and site (10s of metres) nested within each location were also used. In addition, temporal variation over two 6 mo periods was also examined in the Isle of Man and Ireland. Most variability for all population parameters occurred over the largest spatial scale (location). This was a direct result of differences between Sweden and the other 2 locations, the Isle of Man and Ireland, which showed highly similar levels of all population parameters. The population of $S$. balanoides at the Swedish location was characterised by high growth rates, large size, high levels of mortality and a large turnover of bare space. At the spatial scale 'shore', only 1 population parameter, the growth rate of recruits, showed variability. At the smallest scale of 'site', all parameters showed significant variability except growth rate of adults. Calculation of variance components showed that differences between replicates (spatial scale: $<0.5 \mathrm{~m}$ ) accounted for little of the overall variability, in general less than the scales of site and shore. Examination of temporal variability over two 6 mo periods revealed no difference between time periods and no significant interaction between temporal and spatial scales. Thus, there was consistency of spatial variability over time. The potential causes of variability in population parameters of $S$. balanoides at different spatial scales and the implications for future studies are discussed.
\end{abstract}

KEY WORDS: Hierarchical sampling · Intertidal · Population dynamics $\cdot$ Semibalanus balanoides Spatial variation Resale or republication not permitted without written consent of the publisher

\section{INTRODUCTION}

All ecological systems exhibit heterogeneity and patchiness (Levin 1992), and increasingly there is an

*E-mail: stu@liverpool.ac.uk appreciation that ecological phenomena need examining across a range of spatial scales (Underwood 1997). In order to understand how communities function, it is first necessary to adequately describe the pattern, using observational studies to identify the scales at which variability occurs. Experimental studies can 
then be designed to investigate the intensities and rates of processes at relevant rather than arbitrary scales (Underwood \& Petraitis 1993).

Intertidal benthic communities have been studied extensively and have contributed much to our general understanding of population and community dynamics. Acorn barnacles form an important part of intertidal communities world-wide (Stephenson \& Stephenson 1949) and there is an extensive literature on all aspects of their population ecology, including natural levels of mortality (Connell 1961a, 1985, Wethey 1983, Bertness 1989, Gosselin \& Qian 1996), growth rate (Barnes \& Powell 1953, Barnes 1955, Crisp \& Bourget 1985, Bertness et al. 1991, Sanford et al. 1994), intraspecific competition (Connell 1961a, Bertness 1989), and interactions with other species (barnacles: Connell 1961b; mussels: Lively \& Raimondi 1987; limpets: Hawkins 1983, Miller 1989; algae: Menge 1976, Hawkins 1983; predators: Connell 1961a, Johnson et al. 1998). Spatial and temporal variability in settlement and recruitment of barnacles and the consequences of such variation to adult populations have been studied extensively (e.g. Hawkins \& Hartnoll 1982, Caffey 1985, Kendall et al. 1985, Pineda 1994, Carroll 1996). In contrast, very little is known regarding spatial variability in adult population dynamics.

Where large environmental differences between sites occur, for example in the comparison of productive sheltered bays with exposed open shores, population dynamics of acorn barnacles can vary dramatically (e.g. Bertness et al. 1991). Even between sites with similar conditions, variability is apparent. Hyder et al. (1998) documented variability in patterns of cover and size of Semibalanus balanoides at small $(<1 \mathrm{~m})$, meso $(100 \mathrm{~m})$ and large $(>10 \mathrm{~km})$ scales on exposed shores of north Wales, while Benedetti-Cecchi et al. (2000) showed variability in the growth of Chthamalus stellatus in the NW Mediterranean was greatest at the scale of location (100s of kilometres) and at the smallest scale of centimetres. Variability at the scale of metres and 100s of metres was negligible. At very large spatial scales (100s to 1000 s of kilometres) genetic variation and physical differences in the environment may both play roles in the population dynamics of benthic species. Large differences at very small scales $(<1 \mathrm{~m})$ in the density or cover of intertidal organisms (e.g. Underwood \& Chapman 1996, Åberg \& Pavia 1997, Hyder et al. 1998) and in processes such as growth and mortality (e.g. Benedetti-Cecchi et al. 2000) are a common observation on rocky shores. Such variability may be caused by a number of factors operating over small spatial scales, including species interactions, substratum heterogeneity and hydrodynamic processes.

In assessing variability in population dynamics of a species it is possible to compare the results of existing studies from a variety of locations (see for example Crisp \& Bourget 1985 for review of studies on growth rate in Semibalanus balanoides), but unless data are collected in comparable ways at similar spatial and temporal scales their usefulness in this respect is limited (Underwood \& Petraitis 1993). We aimed to determine the spatial scales at which estimates of various population attributes - size distribution, density, \% cover, growth and mortality - vary in the intertidal barnacle $S$. balanoides. Specifically we tested the hypothesis that variation is greatest at very small spatial scales $(<1 \mathrm{~m})$ and very large scales $(100 \mathrm{~s}$ to 1000s of kilometres). $S$. balanoides is an extremely abundant intertidal barnacle with a wide geographical distribution. It is a boreo-arctic species found on both sides of the north Atlantic, and in Europe it extends over a large latitudinal range from NW Spain (Barnes 1958) to Spitzbergen (Barnes 1957). Three locations SW Ireland, the Isle of Man and the west coast of Sweden - which cover a large part of this latitudinal range, were selected to investigate variation on a large spatial scale (100s of kilometres). Within each location, 2 further scales were investigated, shores (1000s of metres) and sites (10s of metres). Variance components were used to assess the degree to which differences at very small scales (between replicates) contribute to overall variability. In addition, temporal variation over two 6 mo periods was assessed in order to determine the degree to which spatial variation was temporally consistent.

\section{MATERIAL AND METHODS}

Study locations. The study covered 2 shores at each of 3 locations: the northern part of the Swedish west coast, close to Tjarnö Marine Biological Laboratory, the south and west coast of the Isle of Man, in the Irish Sea, and the south west coast of Ireland, west of Cork (Fig. 1).

These locations differ in general abiotic conditions. The Swedish area is almost atidal (tidal range $0.3 \mathrm{~m}$ ), but large irregular sea level changes, from about $0.5 \mathrm{~m}$ below to $1.5 \mathrm{~m}$ above mean sea level, occur due to changes in air pressure and winds (Johannesson 1989). Large fluctuations in salinity, around a mean of 24 , are also common, and in about 1 winter in 4 there are periods when ice covers the sea (Johannesson 1989). In contrast, the Isle of Man and the south west coast of Ireland both experience large tidal ranges of up to 7 and $4.5 \mathrm{~m}$ respectively, and have stable fully marine salinities (33 to 34.8 ).

Sampling design. Sampling of Semibalanus balanoides populations was carried out during 1997 and 1998 using a nested design at the locations described 
above. At each location, 2 shores with abundant $S$. balanoides were selected, at least $5 \mathrm{~km}$ apart, which were exposed to wave action. Physical and biological descriptions of the shores are given in Lindegarth et al. (2001), Hartnoll \& Hawkins (1985), and Power (2000) for the Swedish, Isle of Man and SW Ireland sites respectively. On each shore, 5 sites within the centre of the $S$. balanoides zone were selected at least $10 \mathrm{~m}$ apart. All sites were in well-drained areas with an abundance of $S$. balanoides. Steep slopes $\left(>45^{\circ}\right)$ and algaedominated areas were avoided. From this selection of sites, 2 were chosen at random, and at each site 2 randomly located quadrats, between 15 and $50 \mathrm{~cm}$ apart, were sampled.

Each survey involved photographing marked quadrats. The precise protocol differed between locations owing to the different characteristics of barnacle populations and different camera systems. At all locations, however, the use of a fixed frame attached to the camera system and a series of holes drilled in the rock allowed exact relocation of the area. In Ireland, a medium format Bronica ETRS camera with $75 \mathrm{~mm}$ lens was used, allowing an area of $25 \times$ $20 \mathrm{~cm}$ to be photographed at the necessary resolution. Within this area, two $5 \times 5 \mathrm{~cm}$ quadrats were selected at random when photographs were analysed. In the Isle of Man and Sweden, a $35 \mathrm{~mm}$ camera was used to photograph 2 fixed quadrats located randomly within an area of $0.5 \times 0.5 \mathrm{~m}$ at each site. In the Isle of Man, quadrats were $5 \times 5 \mathrm{~cm}$ in size. In Sweden, owing to the larger size of Semibalanus balanoides there, quadrats measured $15 \times 15 \mathrm{~cm}$.

Each quadrat, including a scale bar, was photographed in May/June 1997 using 100 or 200 ASA colour reversal film. Quadrats were photographed again 6 mo later. At the same time, 2 new sites were chosen in the Isle of Man and Ireland and at each site 2 quadrats were photographed. These quadrats were re-photographed 6 mo later in May 1998.

All slides were analysed in Lisbon using imageanalysis software (Image Pro Plus, Media Cybernetics, 1996). All Semibalanus balanoides individuals were counted and the opercular length measured at the beginning $\left(t_{0}\right)$ of each 6 mo period. The presence and size of these individuals was then determined 6 mo later $\left(t_{6}\right)$. In this way, density and population structure were calculated at the beginning and end of each 6 mo period. Mortality and individual growth were calculated as a mean daily value over each 6 mo period. The $\%$ cover of bare space and of other barnacle species was determined by overlaying a 64 -point grid on each slide.

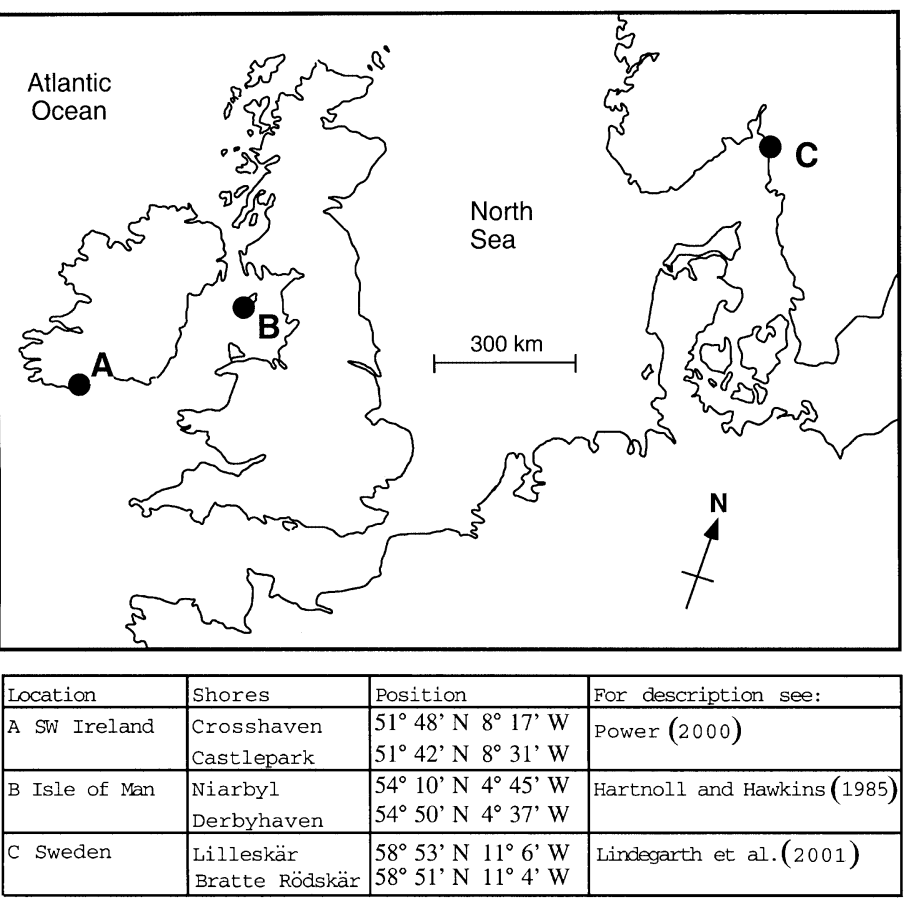

Fig. 1. Map showing the positions of the 3 sampling locations in north-west Europe. A: SW Ireland; B: Isle of Man; C: Sweden

Data analysis. The length frequency distribution of Semibalanus balanoides individuals from each quadrat was plotted. From this distribution a distinct size class of new recruits which had settled in spring 1997 could be recognised at $t_{0}$ of the first 6 mo period (May/June to November/December 1997) at all locations. Determination of population parameters was carried out separately for recruits $(0+)$ and adults $(1+)$. For the second 6 mo period, all individuals were treated as adults $(0.5+)$. Mean growth rate of barnacles was calculated as increase in opercular length per day, and daily instantaneous mortality rate calculated as:

$$
\log _{\mathrm{e}}\left(N_{t_{6}} / N_{t_{0}}\right) / t
$$

where $N_{t_{6}} / N_{t_{0}}$ is the proportion of individuals surviving per quadrat, and $t$ is the number of days between photographs. An estimate of all population parameters was made for each individual quadrat using all barnacles within the quadrat area. The number of barnacles used varied depending on the number present within each quadrat, and for the estimate of growth, the number which survived over the 6 mo sampling period (Table 1).

Population parameters were examined by analysis of variance to determine patterns of spatial and temporal variation. Firstly, all 3 locations were used to examine the spatial scales at which variation in population parameters occurred during the period May/June to 
Table 1. Semibalanus balanoides. Number of barnacles (adults and recruits) analysed per quadrat for different population parameters over the 2 sampling periods (T1 and T2). For the Isle of Man and Ireland, quadrats were $5 \times 5 \mathrm{~cm}$; for Sweden, quadrats were $15 \times 15 \mathrm{~cm}$. nd: no data

\begin{tabular}{|lccc|}
\hline \multicolumn{1}{c}{$\begin{array}{c}\text { T1 May/Jun- } \\
\text { Nov/Dec 1997 }\end{array}$} & $\begin{array}{c}\text { T2 Nov/Dec 1997- } \\
\text { May 1998 } \\
\text { Recruits (0+ yr) }\end{array}$ & Adults (1+ yr) & Adults (0.5+ yr) \\
\hline Density, size, mortality & & \\
Ireland & $36-197$ & $59-87$ & $65-176$ \\
Isle of Man & $24-112$ & $45-122$ & $50-144$ \\
Sweden & $84-664$ & $9-141$ & nd \\
Growth & & & \\
Ireland & $28-93$ & $29-62$ & $47-97$ \\
Isle of Man & $14-64$ & $22-85$ & $39-111$ \\
Sweden & $5-23$ & $5-18$ & nd \\
& & & \\
\hline
\end{tabular}

November/December 1997. The ANOVA model used was a fully nested design with all factors random. The variance components associated with each spatial scale were partitioned and the percentage contribution of each scale to overall variation was determined (Underwood 1997). Secondly, data from the Isle of Man and Ireland were used to examine spatial and temporal variation over a 12 mo period, May 1997 to May 1998. At each shore, at each location, two 6 mo periods were compared; thus the factor time (random) was orthogonal to shore and location. Different sites were used for each 6 mo period, and hence the factor site (random) was nested in the combination of location, shore and time.

Prior to using ANOVA, Cochran's test (Winer 1971) was used to test for heterogeneity of variance and, where necessary, data were transformed. Multiple comparisons of levels within significant factors were made using Student-Newman-Keuls (SNK) tests.

\section{RESULTS}

\section{Size distribution}

Opercular length frequency distributions showed 2 distinct size classes of Semibalanus balanoides in May/June 1997 at all locations (Fig. 2), corresponding to new recruits $(<2$ mo old) and adults ( $>1$ yr old). These size classes in Sweden are more distinct in the frequency distributions for individual quadrats than appears from the combined distribution in Fig. 2. The mean and maximum sizes of recruits in Sweden (2.9 and $5 \mathrm{~mm}$ ) were far higher than in the Isle of Man $(0.8$ and $1.3 \mathrm{~mm}$ ) and Ireland (0.9 and $1.3 \mathrm{~mm})$. Settlement of $S$. balanoides in 1997 occurred earlier in Sweden than at the other 2 locations (Jenkins et al. 2000) such that at the time of sampling, recruits were at least 2 mo old in Sweden compared to only at least $1 \mathrm{wk}$ in the Isle of Man and Ireland. This difference in timing cannot itself explain the much larger size of recruits in Sweden, since the modal size of recruits in Sweden was similar to that of adults at the 2 more southerly locations. Adult $S$. balanoides could not be separated into year classes at any location despite a large range of opercular lengths. The mean and maximum size of adults was far greater in Sweden than at the other 2 locations. Maximum opercular length of individuals in Sweden was $9.1 \mathrm{~mm}$ compared to only 5.5 and $4.4 \mathrm{~mm}$ in the Isle of Man and Ireland respectively.

By early winter of 1997 the discrete recruit size class was no longer obvious and total density had decreased markedly, especially in Sweden. There was little evidence of a bimodal distribution at any location except at Shore 2 in Ireland. As in the May/June distribution, the range and overall size of individuals was far greater in Sweden than in the other 2 locations (Fig. 2).

\section{Spatial variation in population parameters}

Analysis was undertaken separately for new recruits and adults because of inherent differences between them in population variables. The density of adults at the first sampling date in May/June 1997 varied significantly at the spatial scales of location and site (Table 2). Variability among locations was high, with Sweden showing, on average, 10 and 15 times lower density than Ireland and the Isle of Man respectively (Fig. 3). Instantaneous mortality rate varied at the scale of location (mortality was significantly greater in Sweden) and site (Fig. 3, Table 2). Examination of Fig. 3 and the results of SNK tests show that differences between sites occurred at both shores in Sweden but not at the other locations. Mean size and rate of growth of adults were significantly higher in Sweden than at the other locations (Fig. 3, Table 2). The mean opercular length of adults was $6 \mathrm{~mm}$, compared to 2.6 and $2.3 \mathrm{~mm}$ in the Isle of Man and Ireland respectively, whilst growth was over 3 times greater in Sweden than at the other locations. There was no significant effect of the spatial scales of shore or site on growth, although there were significant differences in size between sites.

Calculation of variance components showed that the largest spatial scale, location, contributed by far the most variability of all parameters. There was no consistency in the ranking of variance components for the smaller spatial scales. The factor shore contributed 
May/June 1997

\section{Sweden}
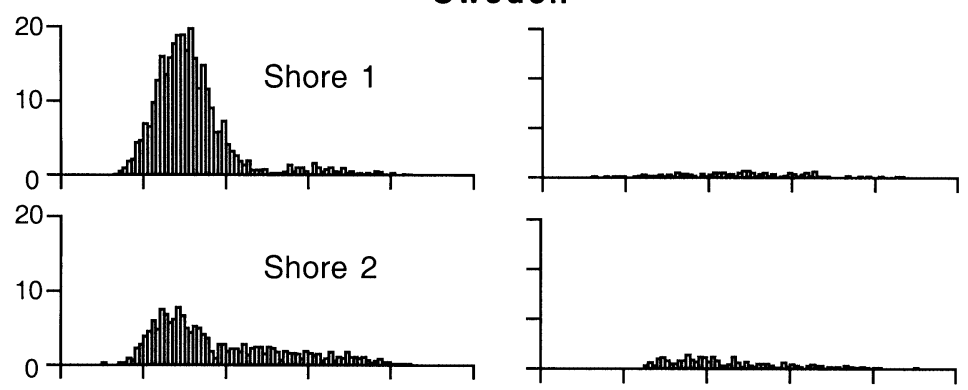

Isle of Man
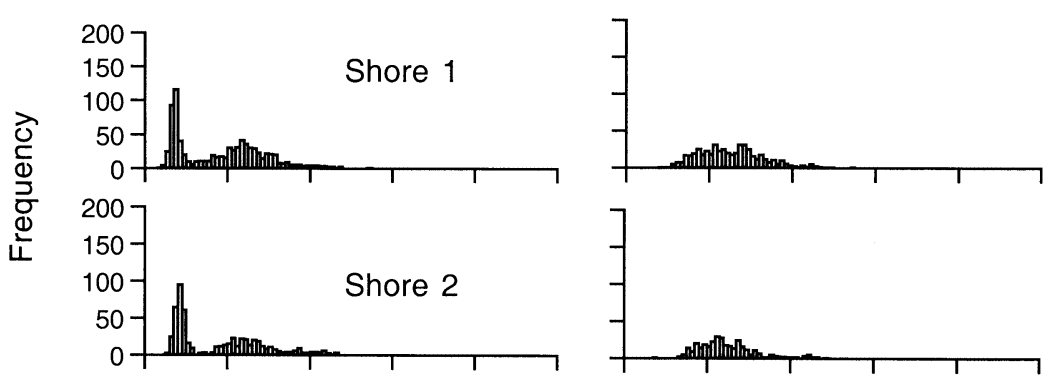

Ireland
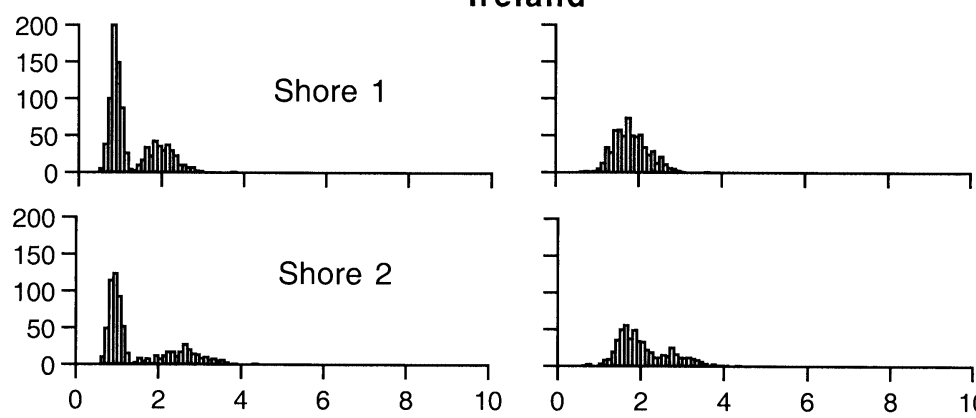

Opercular length $(\mathrm{mm})$

Fig. 2. Semibalanus balanoides. Length-frequency histograms for each shore at each location at the start and finish of the first 6 mo period. Each histogram represents the total from four $5 \times 5 \mathrm{~cm}$ quadrats. Note different $y$-axis scale for Swedish shores

very little to overall variability except in the density of adults, while site explained a large proportion of variability only for adult growth. Differences between replicates accounted for surprisingly little variability for all adult variables.

ANOVA for instantaneous mortality rates of recruits revealed a pattern similar to that shown by adults (Fig. 4). Mortality varied significantly at the spatial scales of location and site (Table 3 ), although variance components showed that the factor location contributed far less to overall variability than in adults. SNK tests showed that mortality was significantly greater in Sweden than in the other 2 locations. The relatively large amount of variation attributable to the factor site, shown by analysis of variance components (Table 3 ), was again predominantly a result of variation between sites in Sweden (SNK tests). However, interestingly, the ranking of sites was not consistent between adults and recruits. In contrast to adults, the growth of recruits was similar at all locations (Fig. 4, Table 3). There was significant variability, however, between shores and between sites. SNK tests showed significant differences between shores in Sweden, and between sites in both Sweden and the Isle of Man. Differences in growth and mortality of recruits between replicates accounted for little of the overall variability (Table 3).

The \% cover of Semibalanus balanoides in May $1997\left(t_{0}\right)$ was similar at all 3 locations, although there were significant differences among shores (Table 4, Fig. 5). Six mo later, variability at all spatial scales had increased owing to variability in the population parameters described above. There were significant differences in \% cover among shores and sites. Overall, the mean \% cover of $S$. balanoides declined from 84 to $24 \%$ and from 78 to $71 \%$ in Sweden and the Isle of Man respectively over the 6 mo period, while in Ireland mean cover remained constant at $70 \%$.

\section{Temporal variation}

Sampling of different quadrats over 2 separate 6 mo periods (May to November 1997 [Period T1] and November 1997 to May 1998 [T2]) in the Isle of Man and Ireland allowed the formal comparison of growth and mortality in Semibalanus balanoides between these periods, and determination of the potential interaction between spatial and temporal scales. Comparison of different periods within a year in a species with seasonal recruitment means that the age range of individuals will differ. For Period T1, analysis was restricted to adults over $1 \mathrm{yr}$ of age, while T2 individuals in all populations were over 6 mo in age and were all included. For both growth and mortality, spatial and temporal interactions were all non significant, and no difference between time periods could be detected (Table 5 , Fig. 6). 
Table 2. Semibalanus balanoides. ANOVA of 4 population parameters in adult (>1 yr old) baranacles for the period May/June 1997 to November/December 1997 over a range of spatial scales. Density and size of barnacles were determined at $t_{0}$ (May/June 1997). Significant values in bold

\begin{tabular}{|c|c|c|c|c|c|c|c|}
\hline & Source & df & MS & $F$ & $\mathrm{p}$ & $\begin{array}{c}\text { Variance } \\
\text { component }\end{array}$ & $\begin{array}{l}\% \text { variance } \\
\text { component }\end{array}$ \\
\hline Density & Location & 2 & 18.19 & 14.61 & $<0.03$ & 2.12 & 83.8 \\
\hline Transform & Shore (Location) & 3 & 1.25 & 3.79 & $>0.07$ & 0.23 & 9.1 \\
\hline $\operatorname{Ln}(x+1)$ & Site[Shore (Location)] & 6 & 0.33 & 13.11 & $<0.0001$ & 0.15 & 5.9 \\
\hline$C=0.2730$ & Residual & 12 & 0.03 & & & 0.03 & 1.2 \\
\hline $\mathrm{p}>0.05$ & Total & 23 & & & & & \\
\hline Mortality & Location & 2 & $1.26 \times 10^{-4}$ & 125.61 & $<0.01$ & $1.56 \times 10^{-5}$ & 76.6 \\
\hline Transform & Shore (Location) & 3 & $1.00 \times 10^{-6}$ & 0.09 & $>0.9$ & $0^{\mathrm{a}}$ & $0^{\mathrm{a}}$ \\
\hline None & Site[Shore (Location)] & 6 & $1.09 \times 10^{-5}$ & 7.93 & $<0.01$ & $4.77 \times 10^{-6}$ & 21.9 \\
\hline$C=0.4326$ & Residual & 12 & $1.37 \times 10^{-6}$ & & & $1.37 \times 10^{-6}$ & 6.3 \\
\hline $\mathrm{p}>0.05$ & Total & 23 & & & & & \\
\hline Size & Location & 2 & 34.36 & 96.87 & $<0.002$ & 4.25 & 96.2 \\
\hline Transform & Shore (Location) & 3 & 0.36 & 1.44 & $>0.30$ & 0.03 & 0.7 \\
\hline None & Site[Shore (Location)] & 6 & 0.25 & 12.44 & $<0.001$ & 0.12 & 2.7 \\
\hline$C=0.4264$ & Residual & 12 & 0.02 & & & 0.02 & 0.5 \\
\hline $\mathrm{p}>0.05$ & Total & 23 & & & & & \\
\hline Growth & Location & 2 & $1.69 \times 10^{-5}$ & 30.44 & $<0.02$ & $2.04 \times 10^{-6}$ & 86.6 \\
\hline Transform: & Shore (Location) & 3 & $5.56 \times 10^{-7}$ & 4.33 & $>0.05$ & $1.07 \times 10^{-7}$ & 4.6 \\
\hline None & Site[Shore (Location)] & 6 & $1.29 \times 10^{-7}$ & 0.61 & $>0.7$ & $0^{\mathrm{a}}$ & $0^{\mathrm{a}}$ \\
\hline$C=0.5400$ & Residual & 12 & $2.10 \times 10^{-7}$ & & & $2.10 \times 10^{-7}$ & 8.8 \\
\hline $\mathrm{p}>0.05$ & Total & 23 & & & & & \\
\hline
\end{tabular}

\section{DISCUSSION}

For all population parameters of Semibalanus balanoides estimated, by far the most variability was attributable to the factor location. Benedetti-Cecchi et al. (2000) made a similar conclusion for growth rates in the barnacle Chthamalus stellatus over a hierarchy of scales up to 100 s of kilometres. Variability in $S$. balanoides populations among locations was a direct result of differences between Sweden and the other 2 locations, the Isle of Man and Ireland, which showed remarkably similar levels of all population variables. The adult population of $S$. balanoides in Sweden was characterised by high growth rates, large size and high levels of mortality. There was a large turnover of bare space in Sweden in contrast to a relatively constant barnacle cover throughout the year on the Isle of Man and in Ireland. In addition, much of the variability at the scales of shore and site were a result of differences at these spatial scales in Sweden.

The distinct difference in the population dynamics in Sweden may be the result of a number of physical factors such as tidal regime, food supply and water temperature. In addition, the level of recruitment and adult density, which was far lower in Sweden than in the Isle of Man or Ireland, may have been one factor causing elevated growth rates. Intense intraspecific competition between crowded barnacles can cause a severe reduction in growth rate (Crisp 1960). However observations in the Isle of Man and Ireland showed that well-spaced individuals attained far lower growth rates and sizes than in Sweden. It therefore seems unlikely that this factor was important. Food supply (measured as surface concentration of chlorophyll a) showed no distinct difference over the period of study between the Isle of Man and Sweden (unpubl. data). Surface water temperatures may affect growth rates through their influence on the rate of cirral beat (Southward 1955, 1957). Temperatures were higher during the summer months in Sweden, but above those at which maximal cirral beat has been recorded in Semibalanus balanoides (Southward 1955). In addition, a comparison of a wide range of studies which have quantified growth in $S$. balanoides on European shores (Runnström 1925, Moore 1934, Hatton 1938, Barnes \& Powell 1953, Feyling-Hannssen 1953, Barnes 1955, Barnes \& Barnes 1962) revealed no latitudinal gradient, indicating that temperature effects are probably less important than other local factors. Growth in intertidal filter-feeders such as barnacles is limited not only by food supply and rate of feeding but also by the time available to feed. Barnes \& Powell (1953) demonstrated an increase in growth of $S$. balanoides with increasing periods of submergence. In areas such as the Baltic Sea, which experiences very low amplitude tides, local conditions of pressure and wind are ex- 

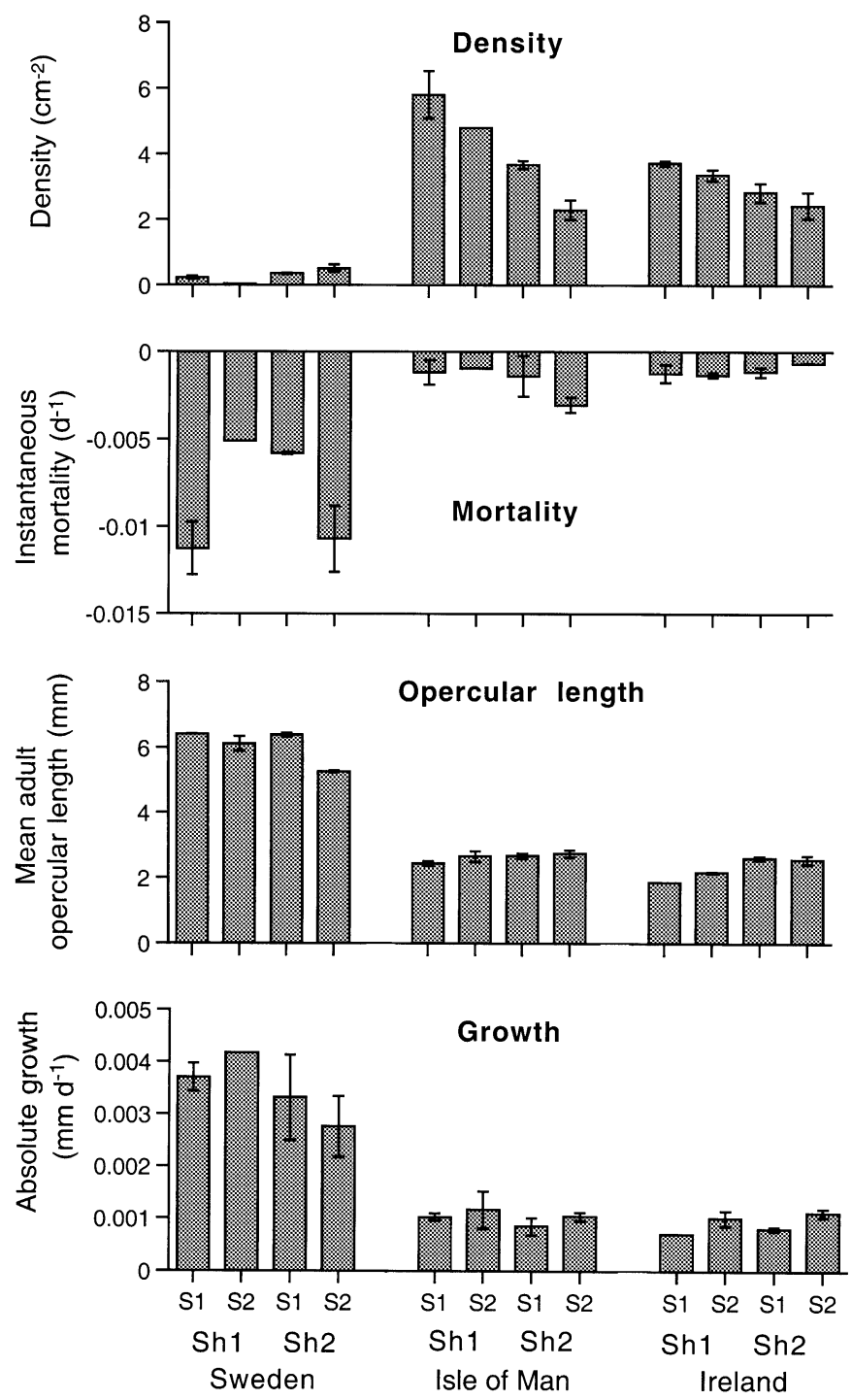

Fig. 3. Semibalanus balanoides. Mean estimates of 4 parameters for the adult population ( $>1 \mathrm{yr}$ old) at the 3 locations for the period May/June 1997 to November/December 1997. Density and opercular length were determined at $t_{0}$. For each location two $5 \times 5 \mathrm{~cm}$ quadrats were sampled at each of 2 sites $(\mathrm{S} 1, \mathrm{~S} 2)$ at each of 2 shores $(\mathrm{Sh} 1, \mathrm{Sh} 2)$. Error bars $= \pm 1 \mathrm{SE}$

tremely important in determining the pattern of emersion and immersion experienced on the shore. At the Swedish location the very small tidal range means that any significant degree of wave action ensures that barnacles are submersed or at least exposed to wave splash. Barnes \& Barnes (1962) observed high rates of growth in $S$. balanoides in Denmark, southern Sweden and north-east Germany and attributed this to the long periods of submergence experienced by littoral organisms in these atidal areas. As well as influencing growth, the pattern of tidal rise and fall may influence mortality rates. Connell (1961b) found high mortality of recruits in periods of calm weather when emersion is increased. Local conditions (high-pressure systems) can result in long periods of continual emersion for intertidal barnacles in areas of low tidal amplitude. This may explain the high rates of mortality of new recruits at the Swedish location and consequent high turnover of bare space. Variability in emersion periods among sites and shores may also explain the large degree of variability at these spatial scales in Sweden compared to the other 2 locations. Another important factor influencing community dynamics on Swedish shores is the occurrence of sea ice. However, this did not develop during the period of our study.

In addition to environmental differences between locations, the possibility of genetic differences should not be overlooked. Given the large-scale dispersal in species such as barnacles with long-lived larvae (e.g. Crisp 1958), Semibalanus balanoides may be genetically homogenous over its distribution area in Europe, as are other barnacles (Chthamalus montagui and C. stellatus) (Pannacciulli et al. 1997). However, there are numerous cases where genetic differences within populations may be maintained despite large-scale patterns of dispersal (e.g. Levinton \& Suchanek 1978, Todd et al. 1988).

At smaller spatial scales, significant differences were found in certain population variables. Differences between shores (1000s of metres) contributed significant variability in only 1 population variable, growth rate of

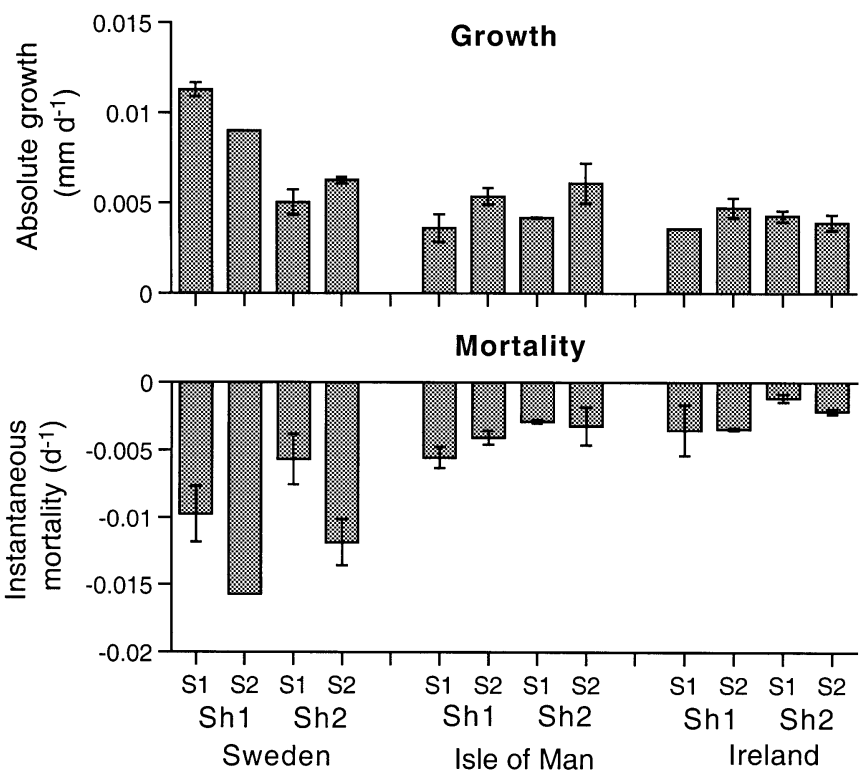

Fig. 4. Semibalanus balanoides. Mean estimates of growth and mortality for new recruits at the 3 locations for the period May/June 1997 to November/December 1997. For each location two $5 \times 5 \mathrm{~cm}$ quadrats were sampled at each of 2 sites (S1,

S2) at each of 2 shores (Sh1, Sh2). Error bars $= \pm 1 \mathrm{SE}$ 
Table 3. Semibalanus balanoides. ANOVA of instantaneous mortality and absolute growth for the period May/June 1997 to November/December 1997 in new recruits over a range of spatial scales. Significant values in bold

\begin{tabular}{|c|c|c|c|c|c|c|c|}
\hline & Source & df & MS & $F$ & $\mathrm{p}$ & $\begin{array}{l}\text { Variance } \\
\text { component }\end{array}$ & $\begin{array}{l}\% \text { variance } \\
\text { component }\end{array}$ \\
\hline Mortality & Location & 2 & $1.54 \times 10^{-4}$ & 10.42 & $<0.05$ & 1.07 & 56.1 \\
\hline Transform & Shore (Location) & 3 & $1.48 \times 10^{-5}$ & 1.15 & $>0.4$ & 0.05 & 2.5 \\
\hline None & Site[Shore (Location)] & 6 & $1.29 \times 10^{-5}$ & 4.48 & $<0.02$ & 0.5 & 26.3 \\
\hline$C=0.2541$ & Residual & 12 & $2.87 \times 10^{-6}$ & & & 0.29 & 15.1 \\
\hline $\mathrm{p}>0.05$ & Total & 23 & & & & & \\
\hline Growth & Location & 2 & $3.26 \times 10^{-5}$ & 2.38 & $>0.2$ & 0.24 & 35.2 \\
\hline Transform & Shore (Location) & 3 & $1.37 \times 10^{-5}$ & 5.49 & $<0.04$ & 0.28 & 41.8 \\
\hline None & Site[Shore (Location)] & 6 & $2.50 \times 10^{-6}$ & 4.60 & $<0.02$ & 0.10 & 14.9 \\
\hline$C=0.3797$ & Residual & 12 & $5.43 \times 10^{-7}$ & & & 0.05 & 8.1 \\
\hline$p>0.05$ & Total & 23 & & & & & \\
\hline
\end{tabular}

Table 4. Semibalanus balanoides. ANOVA of $\%$ cover at $t_{0}$ (May/June 1997) and 6 mo later, $t_{6}$ (November/December 1997), over a range of spatial scales. Significant values in bold

\begin{tabular}{|c|c|c|c|c|c|c|c|}
\hline & Source & df & MS & $F$ & $\mathrm{p}$ & $\begin{array}{l}\text { Variance } \\
\text { component }\end{array}$ & $\begin{array}{l}\% \text { variance } \\
\text { component }\end{array}$ \\
\hline$t_{0}$ & Location & 2 & 0.0392 & 0.55 & $>0.6$ & $0^{\mathrm{a}}$ & $0^{\mathrm{a}}$ \\
\hline Transform & Shore (Location) & 3 & 0.0707 & 12.55 & $<0.01$ & 0.016 & 72.1 \\
\hline None & Site [Shore (Location)] & 6 & 0.0056 & 0.89 & $>0.5$ & $0^{\mathrm{a}}$ & $0^{\mathrm{a}}$ \\
\hline$C=0.2717$ & Residual & 12 & 0.0063 & & & 0.006 & 27.9 \\
\hline $\mathrm{p}>0.05$ & Total & 23 & & & & & \\
\hline$t_{6}$ & Location & 2 & 0.584 & 5.24 & $>0.1$ & 0.059 & 61.6 \\
\hline Transform & Shore (Location) & 3 & 0.111 & 5.13 & $<0.05$ & 0.022 & 23.2 \\
\hline None & Site [Shore (Location)] & 6 & 0.022 & 3.02 & $<0.05$ & 0.008 & 7.8 \\
\hline$C=0.3797$ & Residual & 12 & 0.007 & & & 0.007 & 7.4 \\
\hline $\mathrm{p}>0.05$ & Total & 23 & & & & & \\
\hline
\end{tabular}

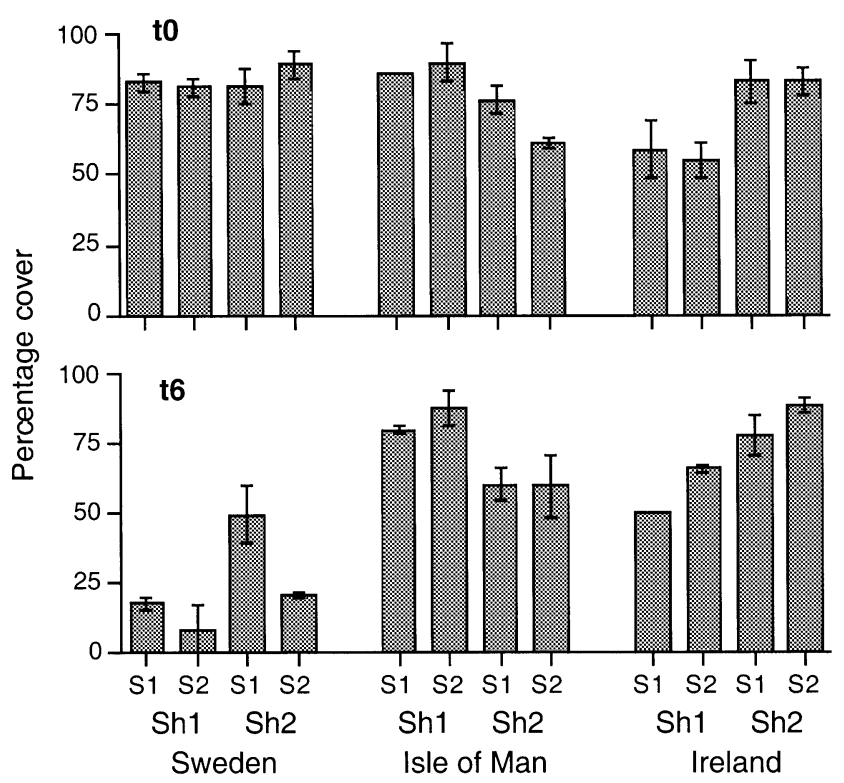

Fig. 5. Semibalanus balanoides. Mean percentage cover for each location at $t_{0}$ (May/June 1997) and 6 mo later at $t_{6}$ (November/December 1997). Error bars $= \pm 1 \mathrm{SE}$ recruits. Thus, within locations, estimates of adult population variables showed no difference between the exposed shores sampled. Hyder et al. (1998) demonstrated variation in free space, population variance (a measure of variability in individual size) and size at the mesoscale $(100 \mathrm{~m})$ in Semibalanus balanoides populations on shores in North Wales, UK, but only found variation between shores in the level of free space. The spatial scale 'shore' may be between the scales at which meso- and large-scale oceanographic processes affect populations (Hyder et al. 1998).

Bertness et al. (1991) demonstrated extreme spatial variation at the spatial scale of 'shore' (5 to $25 \mathrm{~km}$ apart) in the growth rate of Semibalanus balanoides in New England, USA. However, the shores studied covered an extreme environmental gradient from open coast, where food concentrations (measured as watercolumn chlorophyll a concentration) were low, to enclosed bays where concentrations were almost 6 times higher. Early work on $S$. balanoides demonstrated enhanced growth and larger size in localities such as tidal rapids and headlands where water movement 
Table 5. Semibalanus balanoides. ANOVA of instantaneous mortality and absolute growth in adults ( $>6$ mo old) over a range of spatial scales and between 2 time periods: May/June 1997 to November/December 1997 and November/December 1997 to May 1998

\begin{tabular}{|c|c|c|c|c|c|c|}
\hline & Source & df & MS & $F$ & $\mathrm{p}$ & $F$-test over \\
\hline Mortality & Location & 1 & $1.98 \times 10^{-7}$ & & & No test \\
\hline Transform & Shore (Location) & 2 & $4.18 \times 10^{-6}$ & 2.77 & $>0.25$ & $\operatorname{Ti} \times \operatorname{Sh}(\operatorname{Lo})$ \\
\hline None & Time & 1 & $1.28 \times 10^{-6}$ & 1.08 & $>0.4$ & $\mathrm{Lo} \times \mathrm{Ti}$ \\
\hline$C=0.4707$ & Location $\times$ Time & 1 & $1.19 \times 10^{-6}$ & 0.78 & $>0.4$ & $\mathrm{Ti} \times \operatorname{Sh}(\mathrm{Lo})$ \\
\hline \multirow[t]{4}{*}{$p>0.05$} & Sh $($ Lo $) \times$ Time & 2 & $1.51 \times 10^{-6}$ & 1.47 & $>0.25$ & $\operatorname{Si}[\mathrm{Ti} \times \operatorname{Sh}(\mathrm{Lo})]$ \\
\hline & Site $[$ Time $\times($ ShLo $)]$ & 8 & $1.03 \times 10^{-6}$ & 1.26 & $>0.3$ & Residual \\
\hline & Residual & 16 & $8.20 \times 10^{-7}$ & & & \\
\hline & Total & 31 & & & & \\
\hline Growth & Location & 1 & $2.87 \times 10^{-7}$ & & & No test \\
\hline Transform & Shore (Location) & 2 & $1.41 \times 10^{-7}$ & 6.80 & $>0.1$ & $\mathrm{Ti} \times \mathrm{Sh}(\mathrm{Lo})$ \\
\hline None & Time & 1 & $1.10 \times 10^{-7}$ & 2.32 & $>0.3$ & $\mathrm{Lo} \times \mathrm{Ti}$ \\
\hline$C=0.3942$ & Location $\times$ Time & 1 & $4.76 \times 10^{-8}$ & 2.31 & $>0.25$ & $\mathrm{Ti} \times \operatorname{Sh}(\mathrm{Lo})$ \\
\hline \multirow[t]{4}{*}{$\mathrm{p}>0.05$} & $\operatorname{Sh}(\mathrm{Lo}) \times$ Time & 2 & $2.07 \times 10^{-8}$ & 0.21 & $>0.8$ & $\operatorname{Si}[\mathrm{Ti} \times \operatorname{Sh}(\mathrm{Lo})]$ \\
\hline & Site $[$ Time $\times($ ShLo $)]$ & 8 & $1.00 \times 10^{-7}$ & 2.47 & $>0.05$ & Residual \\
\hline & Residual & 16 & $4.04 \times 10^{-8}$ & & & \\
\hline & Total & 31 & & & & \\
\hline
\end{tabular}

transports large quantities of suspended food to the shore (Moore 1934, Hatton 1938). In examining spatial variation between shores we specifically chose shores of similar exposure, and the lack of variability in adult population variables probably reflects the similarity in supply of food between shores. The significant effect of shore on recruit but not adult growth may indicate a greater sensitivity of rapidly growing recruits to slight variability in food supply. Bertness et al. (1991) concluded that predictable variations in the rate of food supply may lead to predictable consequences in the dynamics of adult populations. Our results support this prediction: where food supply rates are predictably similar over scales of kilometres, population dynamics are likely to show little difference. However, new recruits may show greater sensitivity to small environmental differences.

Variation at the level of site over a spatial scale of 10 s of metres was demonstrated for all population variables except adult growth. Thus it appears that greater variability at spatial scales within shores than between them should be expected. It is not clear why this is the case. A variety of factors including substratum heterogeneity (Bergeron \& Bourget 1986), substratum aspect and exposure to wave action (Airoldi \& Virgilio 1998), intra- and interspecific interactions (Connell 1961a) and hydrodynamics (Leonard et al. 1998) can influence patterns and processes at spatial scales in the order of metres. Given the careful selection of sites within relatively strict criteria it seems unlikely that variation in substratum characteristics was important. Very little is known regarding variation in hydrodynamic pro- cesses in the nearshore environment, especially over these scales. Such processes will influence recruitment rates, in addition to nutrient and food supply, and thus may influence population dynamics at small to medium scales.

A number of studies examining the spatial scale of variation in abundance of intertidal and subtidal

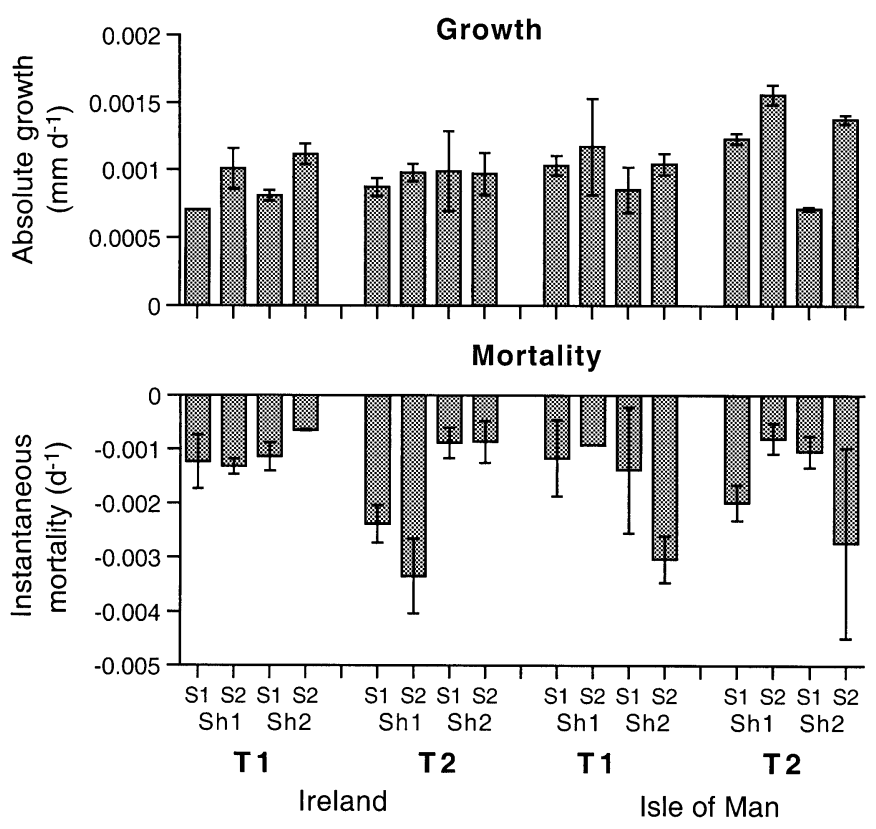

Fig. 6. Semibalanus balanoides. Mean estimates of growth and mortality for barnacles $>6$ mo old at 2 locations for 2 time periods: T1: May/June 1997 to November/December 1997; and T2: November/December 1997 to May 1998. For each location two $5 \times 5 \mathrm{~cm}$ quadrats were sampled at each of 2 sites $(\mathrm{S} 1, \mathrm{~S} 2)$ at each of 2 shores $(\mathrm{Sh} 1, \mathrm{Sh} 2)$. Error bars $= \pm 1 \mathrm{SE}$ 
benthic invertebrates and algae have demonstrated a large degree of variation at the smallest scale: that between individual replicates (Lindegarth et al. 1995, Underwood \& Chapman 1996, Åberg \& Pavia 1997, Hyder et al. 1998). In our study, variation in the abundance of adults between replicates contributed very little to overall variability. However, this is not surprising, given the criteria for selection of sites. More interestingly, variability in rates of processes, growth and mortality was not high, in contrast to the study of Benedetti-Cecchi et al. (2000) on Chthamalus stellatus. Underwood \& Petraitis (1993) considered that over small spatial scales a high degree of variability is to be expected in intertidal habitats owing to the sessile or relatively immobile nature of most species. It is easy to envisage homogeneity in food supply to barnacles over small spatial scales of 10 s of centimetres resulting in low variability in growth. However small-scale variability in factors causing mortality in barnacles would appear likely. Johnson et al. (1998) demonstrated small-scale spatial gradients in predation pressure from dogwhelks centred around crevice refugia. Our selection of topographically simple areas of shore may have limited small-scale variability in predation pressure. Investigation of how environmental heterogeneity affects population dynamics over very small spatial scales may prove useful.

In summary, although mechanisms causing patterns cannot be determined from observational studies such as this, identification of scales of variation does suggest factors which may be important, and determines the correct scales for manipulative experiments to test competing hypotheses. Our results have verified that population dynamics of a species may vary considerably over its range. Surprisingly little variation was shown between replicates. Within a specific region, little variation could be identified between shores of the same type, and it is likely that examination of processes occurring at smaller scales (10s of metres) will be more fruitful. A greater understanding of the nearshore physical environment, in particular hydrodynamic processes, is vital to explaining local variability in demography of benthic species.

Acknowledgements. This study was supported by the Mast III Project EUROROCK, MAS3-CT95-0012. The manuscript was improved by the comments of 4 referees.

\section{LITERATURE CITED}

Åberg P, Pavia H (1997) Temporal and multiple scale variation in juvenile and adult abundance of the brown alga Ascophyllum nodosum. Mar Ecol Prog Ser 158:111-119

Airoldi L, Virgilio M (1998) Responses of turf-forming algae to spatial variations in the deposition of sediments. Mar Ecol Prog Ser 165:271-282
Barnes H (1955) The growth rate of Balanus balanoides (L.). Oikos 6:109-113

Barnes H (1957) The northern limits of Balanus balanoides. Oikos 8:1-15

Barnes H (1958) Regarding the southern limits of Balanus balanoides. Oikos 9:139-157

Barnes H, Barnes M (1962) The distribution and general ecology of Balanus balanoides together with some observations on Balanus improvisus in the waters around the coasts of Denmark, Southern Sweden and north-east Germany. Lunds Univ Arsskr 58:5-41

Barnes H, Powell HT (1953) The growth rate of Balanus balanoides (L.) and $B$. crenatus Brug. under varying conditions of submersion. J Mar Biol Assoc UK 32:107-128

Benedetti-Cecchi L, Acunto S, Bulleri F, Cinelli F (2000) Population ecology of the barnacle Chthamalus stellatus in the northwest Mediterranean. Mar Ecol Prog Ser 198: $157-170$

Bergeron P, Bourget E (1986) Shore topography and spatial partitioning of crevice refuges by sessile epibenthos in an ice disturbed environment. Mar Ecol Prog Ser 28: $129-145$

Bertness MD (1989) Intraspecific competition and facilitation in a northern acorn barnacle population. Ecology 70: $257-268$

Bertness MD, Gaines SD, Bermudez D, Sanford E (1991) Extreme spatial variation in the growth and reproductive output of the acorn barnacle Semibalanus balanoides. Mar Ecol Prog Ser 75:91-100

Caffey HM (1985) Spatial and temporal variation in settlement and recruitment of intertidal barnacles. Ecol Monogr 55:313-332

Carroll ML (1996) Barnacle population dynamics and recruitment regulation in south central Alaska. J Exp Mar Biol Ecol 199:285-302

Connell JH (1961a) The effect of competition, predation by Thais lapillus and other factors on natural populations of the barnacle Balanus balanoides. Ecol Monogr 31:61-104

Connell JH (1961b) The influence of interspecific competition and other factors on the distribution of the barnacle Chthalamus stellatus. Ecology 42:710-723

Connell JH (1985) The consequences of variation in initial settlement vs. post-settlement mortality in rocky intertidal communities. J Exp Mar Biol Ecol 93:11-43

Crisp DJ (1958) The spread of Elminius modestus Darwin in northwest Europe. J Mar Biol Assoc UK 37:483-520

Crisp DJ (1960) Factors influencing growth rate in Balanus balanoides. J Anim Ecol 29:95-116

Crisp DJ, Bourget E (1985) Growth in barnacles. Adv Mar Biol 22:199-244

Feyling-Hannssen RW (1953) The barnacle Balanus balanoides (Linne, 1766) in Spitsbergen. Norsk Polarinst Skr 98:25-32

Gosselin LA, Qian PY (1996) Early post-settlement mortality of an intertidal barnacle: a critical period for survival. Mar Ecol Prog Ser 135:69-75

Hartnoll RG, Hawkins SJ (1985) Patchiness and fluctuations on moderately exposed shores. Ophelia 24:53-64

Hatton H (1938) Essais de bionomie explicative sur quelques especes intercotidales d'algues et d'animaux. Ann Inst Océanogr 17:241-348

Hawkins SJ (1983) Interaction of Patella and macroalgae with settling Semibalanus balanoides (L.) J Exp Mar Biol Ecol 71:55-72

Hawkins SJ, Hartnoll RG (1982) Settlement patterns of Semibalanus balanoides (L.) in the Isle of Man (1977-1981). J Exp Mar Biol Ecol 62:271-283 
Hyder K, Johnson M, Hawkins S, Gurney W (1998) Barnacle demography: evidence for an existing model and spatial scales of variation. Mar Ecol Prog Ser 174:89-99

Jenkins SR, Åberg P, Cervin G, Coleman RA, Delany J, Della Santina P, Hawkins SJ, LaCroix E, Myers AA, Lindegarth M, Power AM, Roberts MF, Hartnoll RG (2000) Spatial and temporal variation in settlement and recruitment of the intertidal barnacle Semibalanus balanoides (L.) (Crustacea: Cirripedia) over a European scale. J Exp Mar Biol Ecol 243:209-225

Johannesson K (1989) The bare zone of Swedish rocky shores: why is it there? Oikos 54:77-86

Johnson M, Hughes R, Burrows M, Hawkins S (1998) Beyond the predation halo: small scale gradients in barnacle populations affected by the relative refuge value of crevices. J Exp Mar Biol Ecol 231:163-170

Kendall MA, Bowman RS, Williamson P, Lewis JR (1985) Annual variation in the recruitment of Semibalanus balanoides on the North Yorkshire coast. J Mar Biol Assoc UK 65:1009-1030

Leonard GH, Levine JM, Schmidt PR, Bertness MD (1998) Flow driven variation in intertidal community structure in a Maine estuary. Ecology 79:1395-1411

Levin S (1992) The problem of pattern and scale in ecology. Ecology 72:1943-1967

Levinton JS, Suchanek TH (1978) Geographic variation, niche breadth and genetic variation at different geographic scales in the mussels Mytilus californianus and M. edulis. Mar Biol 49:363-375

Lindegarth M, André C, Jonsson PR (1995) Analysis of the spatial variability in abundance and age structure of two infaunal bivalves, Cerastoderma edule and C. lamarcki, using hierarchical sampling programs. Mar Ecol Prog Ser 116:85-97

Lindegarth M, Åberg P, Cervin G, Nilsson P (2001) Effects of grazing on the structure of mid-shore, intertidal assemblages on moderately exposed rocky shores of the Swedish west coast. Mar Ecol Prog Ser 212:29-38

Lively CM, Raimondi PT (1987) Desiccation, predation, and mussel-barnacle interactions in the northern Gulf of California. Oecologia 74:304-309

Menge BA (1976) Organization of the New England rocky intertidal community: role of predation, competition and environmental heterogeneity. Ecol Monogr 46: 355-393

Miller KM (1989) The role of spatial and size refuges in the interaction between juvenile barnacles and grazing limpets. J Exp Mar Biol Ecol 134:157-174

Editorial responsibility: Otto Kinne (Editor),

Oldendorf/Luhe, Germany
Moore HB (1934) The relation of shell growth to environment in Patella vulgata. Proc Malacol Soc 21:217-222

Pannacciolli FG, Bishop JDD, Hawkins SJ (1997) Genetic structure of populations of two species of Chthamalus (Crustacea: Cirripedia) in the north-east Atlantic and Mediterranean. Mar Biol 128:73-82

Pineda J (1994) Spatial and temporal patterns in barnacle settlement rate along a southern California rocky shore. Mar Ecol Prog Ser 107:1-2

Runnström S (1925) Zur biologie und entwicklung von Balanus balanoides (Linne). Bergens Mus Årbok 5:1-12

Sanford E, Bermudez D, Bertness MD, Gaines SD (1994) Flow, food supply and acorn barnacle population dynamics. Mar Ecol Prog Ser 104:49-62

Southward AJ (1955) On the behaviour of barnacles. I. The relation of cirral and other activities to temperature. J Mar Biol Assoc UK 34:403-422

Southward AJ (1957) On the behaviour of barnacles. III. Further observations on the influence of temperature and age on cirral activity. J Mar Biol Assoc UK 36:323-334

Stephenson TA, Stephenson A (1949) The universal features of zonation between tidemarks on rocky coasts. J Ecol 38: 289-305

Todd CD, Havenhand JN, Thorpe JP (1988) Genetic differentiation, pelagic larval transport and gene flow between local populations of the intertidal marine mollusc Adalaria proxima (Alder and Hancock). Funct Ecol 2:441-451

Underwood AJ (1997) Experiments in ecology. Their logical design and interpretation using analysis of variance. Cambridge University Press, Cambridge

Underwood AJ, Chapman MG (1996) Scales of spatial patterns of distribution of intertidal invertebrates. Oecologia 107:212-224

Underwood AJ, Petraitis PS (1993) Structure of intertidal assemblages in different locations: how can local processes be compared? In: Ricklefs $\mathrm{R}$, Schluter D (eds) Species diversity in ecological communities. University Chicago Press, Chicago, p 38-51

Wethey DS (1983) Geographic limits and local zonation: the barnacles Semibalanus (Balanus) and Chthamalus in New England. Biol Bull 165:330-341

Wethey DS (1985) Local and regional variation in settlement and survival in the intertidal barnacle Semibalanus balanoides: patterns and consequences. In: Moore PG, Seed R (eds) The ecology of rocky coasts. Hodder \& Stoughton, Sevenoaks, Kent, p 457-468

Winer BJ (1971) Statistical principles in experimental design. McGraw-Hill Kogakusha, Tokyo

Submitted: December 28, 1999; Accepted: December 15, 2000 Proofs received from author(s): July 16, 2001 